\title{
The Wellbeing of Somali Refugees in Kampala: Perceived Satisfaction of their Human Needs
}

\author{
Moses Senkosi Balyejjusa ${ }^{1}$
}

(C) Uganda Martyrs University

\begin{abstract}
Although there is substantial research on the psychological wellbeing of refugees in psychology, especially in acculturation research, there is very little research assessing refugees' objective conditions of living. This study aims to bridge this gap by assessing the perceived satisfaction of Somali refugees' objective elements in Kampala, Uganda. Drawing on qualitative data from 92 Somali refugee and Ugandan participants, the paper shows that the participants assessed the perceived satisfaction of Somali refugees' four objective wellbeing elements (peace and security, housing, education and employment). These objective elements can be seen to represent human needs when analysed in relation to Doyal and Gough's (1991) theory of human need, particularly the intermediate needs. The study participants perceived most Somali refugees as having adequate satisfaction to these objective elements. In this paper I argue that this is the case because of the non-discriminatory and accepting host environment, Somali refugees' financial resources and the culture of social support. These are instrumentally important in promoting Somali refugees' wellbeing since they guarantee adequate satisfaction of the human needs of Somali refugees.
\end{abstract}

Key words $\cdot$ Refugees $\cdot$ Wellbeing $\cdot$ Human needs $\cdot$ Somali refugees $\cdot$ Human wellbeing $\cdot$ Host community

\section{Le bien-être des réfugiés somaliens à Kampala : La satisfaction perçue de leurs besoins humains}

Résumé. Bien qu'il y a beaucoup de recherches sur le bien-être psychologique des réfugiés en psychologie, en particulier dans la recherche d'acculturation, il y a très peu de travaux d'évaluation de leurs conditions objectives de vie. Cette étude vise à combler cette lacune en évaluant la satisfaction perçue des réfugiés somaliens du point de vue de leurs conditons objectives de vie à Kampala, Ouganda. S'appuyant sur des données qualitatives auprès de 92 participants (réfugiés somaliens ainsi que les ougandais), l'article fait montre de l'evaluation de la satisfaction percue des réfugiés somaliens sur quatre elements objectifs de leur bien-être, notamment la paix et la sécurité, le logement, l'éducation, et l'emploi. Ces éléments objectifs peuvent être vus comment représentant les besoins des êtres bumains lorsqu'ils sont analysés par rapport à la théorie de satisfaction des besoins bumains, avanceé par Doyal et Gough (1991). Les participants à cette étude ont percu la plupart des réfugiés somaliens comme ayant une satisfaction adéquate par rapport à ces éléments objectifs. Dans cet article, je soutiens que tel est le cas en raison de la non-discrimination et l'acceptation de l'environnement hôte, des ressources financières des réfugiés somaliens, et de leur culture de soutien social. Ceux-ci sont instrumentalement importants dans la promotion du bien-être des réfugiés somaliens vu qu'ils garantissents leur satisfaction des besoins bumains.

Mots clés: Refugies somaliens $\bullet$ le bien-être $\bullet$ Les besoins humains $\bullet$ Communauté d'accueil

\footnotetext{
${ }^{1}$ Uganda Christian University, Email: senkosi.moses.b@gmail.com
} 


\section{Introduction}

Although Uganda hosts 220,555 refugees (United Nations High Commissioner for Refugees [UNHCR], 2014a), there is very limited research on the status of the satisfaction of their objective human needs. Yet, according to Doyal and Gough (1991), adequate satisfaction of human needs contributes to the wellbeing of human beings. It enables them to avoid objective harm and ensures their very survival and normal functioning (Braybrooke, 1987; Doyal and Gough 1991; Reader, 2005; Wiggins, 1998). Indeed assessing the satisfaction of the human needs of urban refugees in Uganda, Somali refugees inclusive, is necessary since the government policy requires urban refugees to be self-reliant (Government of Uganda [GOU], 2014; UNHCR, 2014b). This means that they are expected neither to receive assistance from the UNHCR and other non-governmental organisations nor the government of Uganda. Therefore, understanding the ways in which urban refugees promote the satisfaction of their human needs is paramount in the presence of such policy environment. It is these ways that need to be strengthened and promoted by agencies working with refugees so as to guarantee continued satisfaction of urban refugees' needs.

Using Somali refugees in Kisenyi as a case study, this paper explores refugees' and host community members' perceptions concerning the status of the satisfaction of Somali refugees' needs in Kisenyi. The paper draws on Doyal and Gough's (1991) theory of human need formulation, specifically the intermediate needs, to assess the satisfaction of Somali refugees' needs. The paper shows that the participants mainly assessed the satisfaction of seven needs of Somali refugees, which include peace and security, housing, education, employment, financial security, food and health care. Although the participants assessed seven needs, this paper focuses on four: peace and security, housing, education, financial security and employment) which were common among the study participants.

The participants perceived majority of Somali refugees as having adequate satisfaction to these needs. I argue that this is the case because of the Somali refugees' financial resources and the culture of social support, and the nondiscriminatory and accepting host environment (refugees act and host community members' attitudes and behaviours). Because of the Refugee Act and host community members' attitudes and behaviours, Somali refugees are able to have peace and security, housing, employment and education. In addition, Somali refugees with financial resources were able to meet their housing, employment and educational needs. Furthermore, because of the culture of social support, Somali refugees with more financial resources were able to give financial assistance to financially less fortunate Somali refugees. This enabled the less fortunate to meet their housing, educational and employment needs.

The paper gives a brief overview of the meaning of the term "needs", a description of Doyal and Gough's theory of human need and a justification for drawing on it to perform the task at hand. The second section discusses the methodology used for data collection. The third section presents the findings of the study. The paper concludes by showing that financial resources and a non- 
discriminatory and accepting host environment, and the culture of social support are instrumental in promoting the satisfaction of Somali refugees' needs and their wellbeing.

\section{Concept of needs and Theory of Human Need (THN)}

Although the concept of human needs has a long history, it has multiple and conflicting meanings. The term can be used as a noun, verb or method/satisfier of desires and drives (Doyal and Gough, 1991; Gasper, 2007; O'Neill, 2011; Rauschmayer et al., 2011). However, this paper adopts Doyal and Gough's (1991) definition of human needs (basic/primary and intermediate) as universal goals which when adequately satisfied enable individuals to avoid serious objective harm. Thus, needs are viewed as necessities/requisites for achieving a given end (Gasper, 2004; 2007; Doyal and Gough, 1991; Phillips, 2006). In this case the end is human wellbeing, which is through avoidance of objective harm to an individual. The objective harm may take the form of malnutrition, stunted growth, ill-health, bodily injuries, ignorance, pre-mature deaths, etc. (Doyal and Gough, 1991).

According to Doyal and Gough, there are two universal basic/primary needs: physical health and autonomy, which must be satisfied optimally in order to avoid the objective harm. Doyal and Gough (1991) argue that these two basic needs are similar to functioning under the capability approach such as being nourished, healthy, literate and numerate (educated) and sheltered. In order to optimally satisfy the basic needs, eleven intermediate needs must be satisfied minimally (Doyal and Gough, 1991; Gough, 2000; Phillip, 2006; Scott, 2012). The intermediate needs are satisfiers of the universal basic needs given that they share universal satisfier characteristics. Universal satisfier characteristics are 'those properties of goods, services, activities and relationships which enhance physical health and human autonomy in all cultures' (Doyal and Gough, 1991: 157). Therefore, the intermediate needs include nutritional food and clean water, protective housing, non-hazardous work environment, nonhazardous physical environment, safe birth control and child-bearing, appropriate health care, security in childhood, significant primary relationships, physical security, economic security, and appropriate education (Dean, 2010; Gasper, 2004; Doyal and Gough, 1991; Gough; 2000; 2003). Although Doyal and Gough (1991) discuss universal societal pre-conditions (production, reproduction, cultural transmission and political authority) for need satisfactions and survival of societies, these are not discussed in detail because the paper focuses on human needs.

THN is adopted for this paper because its listed needs conform to Alkire's (2005) suggestion of framing needs in a general way which allows both universal application and local specification and implementation. In line with Alkire's suggestion, THN needs are universal, but their satisfiers (actual goods and services) vary from one society to another (Clark and Gough, 2005; Gough, 2000). This means that, although the primary and intermediate needs apply to all cultures, their satisfiers are relative (applying to specific local contexts). Secondly, the theory has a logical and relational four step process of explaining human needs. This also fits in well with Braybrooke's (1987) suggested relational formula to be followed while discussing human needs. The relational formula helps us to understand the importance of the claimed needs, 
and reduces on the confusion that arises due to the various usages of term needs (Braybrooke, 1987; Gasper, 2004).

\section{Methodology}

Field work for this project (derived from a PhD study) was carried out between July and December 2013 using qualitative approaches. Data were collected from both Somali refugees and Ugandans living in Kisenyi, a slum in Kampala. This is because most Somali refugees in Kampala live in Kisenyi (Omata, 2012). Approximately 70 Somali refugees and 22 Ugandans were purposively recruited for the study. All the study participants were aged between 18 and 60 years and they included both women and men. Out of the 70 Somali refugees, 14 were recruited to participate in in-depth individual interviews while 56 in focus group discussions (FGDs). All the 22 Ugandans participated in in-depth individual interviews. There were no FGDs for Ugandans because the potential Ugandan FGD participants refused to be recruited into FGDs arguing that they did not have time since they were busy.

In-depth individual interviews were carried out at various places in Kisenyi convenient to the study participants. I conducted the individual interviews with five female and nine male Somali refugee participants with the assistance of translators. I also conducted individual interviews with eight female and fourteen male Ugandan participants in Luganda. Men showed more willingness to participate in the study than women. Since participation in the study was voluntary, the study recruited more male participants than female participants. Individual in-depth interviews were used as a method of data collection because, as Boeije (2010) and Marshall and Rossman (2006) argue, they give an opportunity to the study participants to discuss the study issues in their own words. This fits well especially with a study looking at the participants' perceptions of Somali refugees' wellbeing.

In addition to the individual interviews, seven FGDs were carried out with Somali refugees. Four of the FGDs were carried at Kyaggwe Primary School, one from Refugee Hope and two from a house in Kisenyi. With the exception of the two FGDs at a house in Kisenyi with only male participants, the rest of the FGDs had a combination of both female and male participants. Each FGD had between seven and nine participants, and on average four to five participants were women. Although it had originally been planned to have gender segregated FGDs, potential female participants were unwilling to participate in FGDs conducted by a male researcher without male Somali refugees. They claimed that this was for religious reasons. This could have influenced the female participants' views since they are from a male dominated society. They could have given specific responses to avoid contradiction with the views given by their male counterparts. Like the individual interviews with Somali refugee participants, the FGDs were also carried out with the help of translators and I moderated all the sessions.

FGDs were used as a method of data collection because this study is looking at Somali refugees' wellbeing at the group level, and not at the individual level. The group context, that is, the presence of others, and views of group members have effects on individual participants' views and behaviours (Boeije, 2010). This results 
in collection of data which are not about the experiences and opinions of the individual participants, but about the group as generated through the interaction (Green and Hart, 1999; Hennink, Hutter and Bailey, 2011; Morgan, 1997). All the interviews and FGDs were audio recorded with informed consent of the participants.

Using NVIvo 9, themes, sub-themes, categories and sub-categories were developed. Through comparing the codes for similarities and differences, data were grouped into categories and sub-categories. Themes and sub-themes were developed by comparing categories and sub-categories (Boeije, 2010; Glesne, 2011; Strauss and Corbin, 1998).

\section{Study findings}

As earlier noted, although the participants assessed the perceived satisfaction of seven needs, this paper focused on four (peace and security, housing, education and employment). These elements are similar to Doyal and Gough's (1991) intermediate needs of physical security, protective housing, appropriate education and nonhazardous work environment. Each of these elements is discussed in detail below. Important to note is that the terms "wellbeing" and "living well" are used interchangeably in this paper since they have similar meanings.

\section{Peace and security}

The participants evaluated Somali refugees' peace and security in Kisenyi. Contrary to Doyal and Gough (1991), who define physical security as absence of violence and criminality, peace and security according to the participants included absence of war/violence, freedom of movement and choice, law and order, and psychological peace/security or peace of mind. This echoes other authors' observations such as Barash and Webel (2002), Brunk (2012) and Galtung (2012) who maintain that peace includes both negative (absence of war/violence) and positive (harmony, love, gentleness, freedom, etc.) aspects. For instance, Cortright (2008: 13) argues that "in African traditions peace means order, harmony, and equilibrium, not merely preventing war."

The participants noted that most Somali refugees in Kisenyi have peace and security. Apart from living in a place without war, they are generally not persecuted by the local host community or the government. The host community on the whole does not discriminate or fight against Somali refugees. They have warmly welcomed Somali refugees by renting housing and giving practical advice and assistance (directions to places). Ugandans, especially the house owners and police, give advice to Somali refugees on how to promote their security. They are advised to go back to their homes before it is dark or late in the night to avoid criminals who target night travellers. Some Ugandans also apprehend petty thieves targeting Somali refugees.

Somali refugees also have freedom to do whatever they want as long as it does not conflict with the laws of the country. For instance, they have freedom of worship and freedom of movement to any place and at any time of the day. Somali refugees contribute to this peace and security by interacting and making friendships with Ugandans. Peace and security was perceived by the participants as the only way 
Somali refugees' lives can be safe. When they have peace and security they are able to engage in other undertakings that are fundamental to living well such as starting business enterprises, going to work and studying. For instance, a male youth (Somali refugee) in one FGD observed as follows in relation to Somali refugees' enjoyment of peace and security in Kisenyi: "we have peace. I want to say this, sometimes we go to watch movies and we go back home late in the night and nothing happens to you. Nobody attacks or fights you. There is security here." While Musa (Somali refugee) in an individual interview explained:

We are satisfied with the peace and security. There is law and order; there is a government controlling and securing the country. Nobody can fight like in Somalia. In Somalia, there is tribalism and fighting based on clans; there is no peace there. So, we are very much satisfied with life here and actually we appreciate.

On the side of the Ugandan participants Saida had this to say:

They tell us that in their own country (Somalia), they were no longer able to sleep at night. That when one had just put his/her head down (to sleep), someone would kick the door to the house, torture and do to them whatever he wants. But here, they are doing well; they tell us that they can sleep and wake up at 2:00 a.m. without anyone interfering. 'Don't you see that they are living well here?' Peace and freedom are very important for one to live well. They have a lot of freedom here.

In addition, Jane (Ugandan participant) noted:

I think it is the environment; there is peace. I think Somalis have peace. They tell us that Uganda is a very good place. [For example,] He wakes up in the morning and parks his car there. He sits in a restaurant to take tea as watches television. Then at noon he drives to another restaurant to have lunch. In the evening, he drives his car; he does not do anything, but driving and eating. I am not saying that they don't work, but these people have peace. When you may pass here in the evening, you find them seated outside cross legged and taking tea; they have peace. They are living well.

In contrast to their lives in Somalia, Somali refugees are perceived to be enjoying peace and security in Kisenyi. This is due to the prevailing political stability in Uganda. Unlike Somalia, there is no war going on in places where they live. The war in Somalia created situations of generalised violence and criminality, as noted by Saida and Musa above. Similar to the observation by Doyal and Gough (1991), this inhibits the enjoyment of peace and security. Because there is no war going on and there is a functioning government in Uganda, there is minimal violence and generalised criminality.

Furthermore, Somali refugees have peace and security because of the nondiscriminatory behaviours of Ugandans towards Somali refugees as indicated by some of the participants' observations above. Ugandans do not persecute or harass Somali refugees, even though it would be easy since Somali refugees are physically and culturally different from Ugandans and they are a minority group. Ugandans are involved in behaviours aimed at protecting Somali refugees such as arresting thieves targeting Somali refugees and giving advice on how Somali refugees can avoid falling in the traps of thieves. This means that for immigrants in general and refugees in particular, to have peace, even in a country where there is no war, there must be the 
good will of the host community. This includes the host community having a positive attitude towards refugees.

In addition, the 2006 Refugee Act grants freedoms and rights to refugees such as freedom of movement (GOU, 2006). All these (political stability, a nondiscriminatory host community and the Refugee Act) create an environment which is peaceful and secure. It is this peaceful and secure environment in Kisenyi that enables Somali refugees to engage in tasks and activities that are important to living well, such as attending school, running business enterprises, moving from one place to another and at any time of the day, and engaging in pastime activities. Therefore, Somali refugees are perceived to be enjoying peace and security in Uganda compared to when they were in Somalia.

The role of the non-discriminatory host environment in Somali refugees' wellbeing is comparable to research on immigrants' subjective wellbeing in Australia (Correa-Velec et al., 2010) and Finland (Jasinskaja-Lahti et al., 2006). Although not focusing on objective wellbeing (external to the individual) as the present study does, both studies found that individuals who experienced discrimination by the host community members had lower levels of subjective wellbeing (internal to the individual). For instance, Correa-Velec et al. (2010), in a study of 97 refugee youths in Melbourne, found that youths who had experienced bullying at school and discrimination due to their ethnicity, religion and colour reported lower subjective wellbeing. This means that a non-discriminatory and accepting host environment is instrumental in guaranteeing refugees' wellbeing, both subjective and objective.

It is important, however, to point out that Somali refugees' behaviour of interacting with Ugandans is, in part, responsible for the peace and security they enjoy. It is through interacting with Ugandan house owners and police officers that Somali refugees receive advice on security actions they should take. Nevertheless, this still can only happen when Ugandans engage in non-discriminatory behaviours towards Somali refugees.

A small number of Somali refugee participants also perceived themselves as enjoying peace and security in Uganda because they compared their life in Kenya and Uganda. For instance, a male youth (Somali refugee) in one of the FGDs had this to say about peace and security:

As for me, I am very satisfied with life here (Uganda) because when I compare refugee life here and Kenya, refugees in Uganda are well off. There is a big difference. This is because we have never heard the Uganda government saying Somali refugees should go back to Somalia. We don't live in fear or threat of being chased; we have peace.

The 2006 Refugee Act is the reason why Somali refugees have never been threatened with deportation by the government of Uganda. The act is very generous in terms of rights and freedoms granted to refugees, such as a right to remain in Uganda and fair and just treatment without discrimination based on race, religion, sex, nationality and ethnic identity. In fact, according to the Act, being granted refugee status is considered a human right (GOU, 2006). It also clearly specifies the 
conditions for qualification, disqualification and cessation of refugee status. The government of Uganda is keen on implementing it. Therefore, refugees, including Somali refugees, cannot be summarily deported from Uganda. This results in peace, at least peace of mind or psychological peace, as pointed out by the participant above.

Although living in fear of being deported back to Somalia does not create physical violence, it negatively affects one's psychological peace. This may lead to one developing mental illnesses due to living under constant stress and distress (Doyal and Gough, 1991). This suggests that 'psychological peace' promotes Somali refugees' wellbeing since Doyal and Gough (1991) observe that mental health is a component of physical health, which is a requirement for avoiding objective harm. In addition, Somali refugees having 'psychological peace' means that they may successfully engage in tasks and activities that are essential to living well, such as attending school, running business enterprises and engaging in pastime activities. For example, one can only think of starting a business enterprise if he/she is convinced that he/she will not be deported, at least in the short run.

\section{Employment}

The participants also assessed Somali refugees' employment situation in Kisenyi. Similar to Divakalala's (2008) research on wellbeing in Sri Lanka, employment was considered important by the participants in part because it guarantees financial security, which enables people to acquire other elements important to living well, such as housing, health care and education. However, unlike Doyal and Gough's (1991) work that mainly focuses on a non-hazardous work environment, the participants in this study were concerned with Somali refugees being employed, either through self-employment or by others.

The participants noted that most Somali refugees are employed. Some Somali refugees have started business enterprises such as supermarkets, shops, fuel stations and restaurants. It is in these Somali refugee owned businesses that most Somali refugees have acquired employment. The behaviours of Ugandans towards Somali refugees are, in some ways, responsible for the development of Somali refugees' business enterprises. The participants pointed out that it is Ugandan house owners who rent out shops where Somali refugees run their businesses. It was also pointed out that Ugandans in Kisenyi buy from these business enterprises. As a result, the Somali refugee business enterprises have employed Ugandans as sales persons. For instance, a male Somali refugee participant in one of the FGDs explained:

Let me tell you one fact, Somali refugees are composed of two groups. Those who are financially well off and those who are not. Mostly those who are well off are the ones living here in Kampala and those who are poor live in Nakivale (a refugee settlement in Isingiro district in the western part of Uganda). It is the financially well off Somali refugees who have started businesses where we work. So, we get jobs among ourselves in Kampala. We create jobs for poor people (Somali refugees). For instance, some Somali girls cook for Somali students at university campuses.

Hadijah (Somali refugee) in an individual interview commented: 
Here in Kampala, we are able to work so that we can meet our needs such as housing, health care, education for our children and food. We have started businesses such as shops which sell all kinds of goods. We sell to both Uganda and Somali customers. We don't discriminate and Ugandans don't discriminate against us. The money we get from our businesses we use it to pay the bills.

On the other hand, Wilson (Ugandan participant) when asked where Somali refugees get employment, he replied:

The Somalis work together. They usually pool financial resources so as to start running businesses. The businesses first will give them money, but secondly, they create employment for fellow Somalis. It is these businesses that employ most Somali refugees. They are living well because of working together.

Somali refugees in Kisenyi are able to obtain employment due to their strong financial position and possession of social support. It is Somali refugees with financial resources who have invested in self-employment ventures. It would be hard for Somali refugees to access employment without financial resources to invest in self-employment ventures since Uganda's youth unemployment stands at $61.1 \%$ (ActionAid International Uganda, 2012). This suggests that Somali refugees who are not nationals have much fewer opportunities for accessing employment if they have not started their own employment ventures. In any case, the majority of Ugandans are engaged in self-employment (Uganda Bureau of Statistics, 2013). Therefore, for Somali refugees to access employment in Kampala, they need financial resources to invest in self-employment ventures. This is why it is the financially well off Somali refugees that have managed to migrate from refugee settlements to Kampala, since they are able to create their own employment.

Other Somali refugees who are not financially well off find employment in Somali refugee owned business enterprises. Financially well off Somali refugees engage in creating employment opportunities for financially poor Somali refugees. This is because of a strong culture of social support among Somali refugees. This finding shows that Somali refugees perceive employment of Somali refugees in Kisenyi as a collective responsibility. Furthermore, due to the strong culture of social support, Somali refugees are also able to pool financial resources to start self-employment ventures. All these examples demonstrate the role of social support in enabling Somali refugees' access to employment in Kisenyi.

Ugandans not engaging in discriminatory behaviours is also one of the reasons why Somali refugees operate business enterprises. In order for Somali refugees to run the business enterprises they need space in the form of shops. Due to nondiscriminatory behaviours of Ugandan house owners, Somali refugees are able to have access to housing, as pointed out earlier on. Without housing for business purposes, it would be hard for Somali refugees to venture into business. In addition, Ugandans do not discriminate against Somali refugee owned businesses when it comes to purchasing goods. Since Ugandans are the majority in Kisenyi, this expands the customer base for Somali refugee owned businesses. This, in turn, creates more employment opportunities for Somali refugees since they have a big customer base to serve. Furthermore, in order for Ugandan owned businesses to attract and effectively 
serve the Somali refugee customers, they are employing Somali refugees as sale persons. All these non-discriminatory behaviours of Ugandans have created employment opportunities for Somali refugees.

However, the non-discriminatory behaviours of Somali refugee business owners also, in part, contribute to Somali refugee employment. In order for Somali refugees to successfully operate businesses in a Ugandan dominated Kisenyi, they need sales persons who understand the local languages. Since Somali refugee business owners do not discriminate against Ugandans in terms of employee recruitment, they are able to start and successfully operate business enterprises. In addition, Somali refugee business owners' non-discrimination towards Ugandan customers has also expanded their customer base, which, in turn expands the number of sales persons employed, including Somali refugees, especially those who understand the local languages. This ensures that Somali refugees have access to employment in Kisenyi. This further demonstrates the role of Somali refugees' non-discriminatory behaviours in enabling them access employment in Kisenyi. It should be noted that Somali refugees' nondiscriminatory behaviours can only contribute to Somali refugees' employment if Ugandans are non-discriminatory in the first place. Ugandans being the host community and the majority places them in a more powerful position vis-à-vis Somali refugees.

It is interesting that the participants were not concerned with a non-hazardous work environment, which is an element of Doyal and Gough's (1991) framework. It seems that the non-hazardous work environment is more of a developed and industrialised world concept. Citizens and residents of these countries have alternative mechanisms to live well without a job, such as social welfare programmes. They also have alternative employment opportunities to choose from. However, Somali refugees in Uganda do not have alternatives in terms of employment since the majority of people in Uganda are engaged in self-employment, and there is a high rate of unemployment, as illustrated above. In such circumstances an individual would not be pre-occupied with having non-hazardous employment, but just employment. In addition, non-hazardous requirements in relation to employment are more likely to apply to formal employment ventures than informal employment (self-employment or private employment ventures), especially if the ventures are small and medium scale, as is the case with those started by Somali refugees.

\section{Education}

The participants in addition evaluated Somali refugees' access to education. According to Doyal and Gough (1991), education includes information, knowledge, understanding, attitudes, skills and capacity. It is however, not clear whether the participants held similar views to Doyal and Gough's on what constitutes education. Similar to Doyal and Gough's (1991) work, education was considered important due to its ability to expand one's autonomy and skills acquisition. This partly prepares individuals for future employment, which is similar to Divakalala's (2008) finding on wellbeing in Sri Lanka. Besides, education was considered important because it enables individuals to engage in intercultural communication. The participants 
maintained that Somali refugees (children and youths) have access to education. Somali refugee children attend both public schools which are free of charge and private schools where students pay school fees. Also, the Somali refugee participants noted that their Ugandan friends advise them about the schools providing quality education. For instance, a female participant (Somali refugee) in one of FGD commented: "Our children are able to go to school because of our money. Some people get it from their businesses and others from relatives and friends." Maimuna, in an individual interview, had this to say about the education of Somali refugee children:

Somali children go to school. For instance, some Somali children attend Ugandan owned schools with Ugandan children, and the schools fees are affordable. However, most of these schools don't provide quality education, but it is better than nothing. Some of these schools are government owned. However, we don't go near most privately owned schools because they are very expensive and we can't afford them.

On the other hand, Jalia (Ugandan participant) had this to say about Somali refugees' access to education:

However, when it is school time, you may go around this area and you don't find school going children at home. Even Somalis' children are going to school. If you go to special schools owned by Somalis, the school fees are very high; they are the most expensive schools in this area. They are up there, two of them. There is a mosque for Somalis called Tawqhid; that is where one of the schools is. At that school, most of the students are Somalis and they pay 520,000/= per term. It is not easy to find a Somali child of school-going age not attending school.

As in the case with employment, Somali refugee children and youths access education as a result of their parents' strong financial status. These are mainly Somali refugees operating business enterprises. With incomes from the business enterprises, they are able to pay school fees in private schools and universities, as Jalia explained above. It is the financially poor Somali refugee children who attend universal primary and secondary schools, since they provide free education. However, these schools only cater for tuition fees. The parents and guardians have to incur costs for scholastic materials and items such as books, pens, school uniforms, feeding and medical care (GOU, 2008). This suggests that even Somali refugee children from poor families are partly able to access education in universal primary and secondary schools due to their parents' financial resources. If the financially poor Somali refugees were unable to pay for the scholastic materials and items, their children would not be able to afford universal primary and secondary education. This shows that Somali refugee parents prioritise and value the education of their children.

The fact that Somali refugee children attend schools dominated by Ugandans means that most likely Ugandan children and teachers do not discriminate them. In fact, no acts of discrimination against Somali refugee children by their Ugandan peers were mentioned by any Somali refugee participant. If Ugandan children and teachers were discriminating against Somali refugee children, it is more likely that they would drop out of the schools. In addition, Somali refugees receive advice about schools providing quality education from Ugandans on account of the non-discriminatory behaviours towards Somali refugees. This results in Somali refugees accessing quality 
education since it is Ugandans who are more knowledgeable about the schools in Kisenyi and Kampala because they have lived there longer than Somali refugees.

However, for Somali refugee children to attend Ugandan dominated schools they themselves need to have non-discriminatory attitudes and behaviours. If they were discriminatory tendencies towards Ugandan children, they would stay away from the Ugandan dominated schools. Even the behaviour of seeking advice about schools with quality education can only happen when Somali refugees are not discriminatory towards Ugandans. Therefore, Somali refugees' non-discriminatory behaviours towards Ugandans are in some respects contributing to their children's access to education.

An interesting facet of this finding is the issue of quality of education raised by the participants. This suggests that Somali refugees are not just focused on having education, but on quality education in particular. This idea is related to Doyal and Gough's (1991) work, who argue that education should be appropriate. It is the appropriate/quality education which promotes human wellbeing. However, the findings suggest that poor quality education is better than no education at all. This is due to the fact that poor quality education potentially has some elements/aspects that are useful in life. For instance, although an individual may not acquire all the expected skills, he/she will still learn some skills such as language and social interaction.

\section{Housing}

Finally, the participants also assessed Somali refugees' access to housing in Kisenyi. This element is related to Doyal and Gough's (1991) intermediate need of protective housing (adequate space and sanitation, protection from climatic extremes, dangerous animals, pests and disease carrying vectors). According to the participants, housing includes availability of houses and ability to pay house rent. The participants noted that Somali refugees have adequate access to housing. Somali refugees rent houses from Ugandan house owners. Some Somali refugees in a stronger financial position lease houses with many units, which they sublet to fellow Somali refugees. Furthermore, Somali refugees utilise the services of Ugandan house brokers to secure housing. Nonetheless, Somali refugees who have lived in Kisenyi for a long time get houses by themselves, without utilising the services of Ugandan house brokers. Somali refugees who have lived in Kisenyi for a long time always give advice and help in looking for housing for new arrivals. Those who have lived in Kisenyi for a long time have Ugandan friends who advise them about good quality housing. This reduces the chances of Somali refugees being cheated by landlords in terms of house rent. For instance, Sulait (Ugandan participant) had this to say about Somali refugees' housing in Kisenyi:

I am talking about their (Somali refugees) housing. For me, as a Ugandan, I can't afford renting a house of one million a month, but most Somalis are renting houses in that range. What they get from their businesses helps them; what they get from the UN helps them; what they get from different relatives living abroad helps them. So, you find that they are having different sources of income. When you are up there in 
Kisenyi, you will find that most of them have small shops and Forex bureaus. They are involved in legal one and illegal money transfers.

A male Somali refugee participant in a FGD commented:

The houses we are living in are for Ugandans. While renting these houses from Ugandans, the first thing we do is to pay rent in cash for two years. This means we will not be worried about paying rent for two years.

In another FGD, a female Somali refugee participant noted: "The first thing we have because of Ugandans is the warm welcome; we feel at home. Secondly, they rent to us houses; they sympathise with us and sometimes, they give us discounts."

Like employment and education, Somali refugees are able to access housing because of their financial resources. They have multiple sources of income such as business enterprises and financial remittances from relatives abroad. With this income from these two sources, they are able to pay for housing. It is this stronger financial position of Somali refugees that accounts for their residing in better housing than some Ugandans.

The claim that Somali refugees receive financial support from the UN is unlikely to be true. There is no single Somali refugee participant who mentioned it. Furthermore, as noted earlier, urban refugees in Uganda are expected to be self-reliant in terms of their welfare. The government of Uganda and the UNHCR are not supposed to provide accommodation and material assistance to refugees in Kampala (GOU, 2014). They can only do so during life-saving circumstances, and it should only be a one-off event. In fact, refugees who are unable to sustain themselves in Kampala are supposed to approach the Office of the Prime Minister for relocation to the refugee settlements (GOU, 2014). With this kind of a policy, it is not possible for Somali refugees to receive financial assistance from the UNHCR. Therefore, instead Somali refugees are compelled to access housing by drawing on their own financial resources, from business enterprises and remittances from relatives abroad.

The views of Ugandan participants concerning Somali refugee housing are characterised by a comparison between the housing status for Ugandans and Somali refugees, and not based on internationally acceptable housing standards. According to Doyal and Gough (1991), acceptable housing should be able to protect someone from physical, environmental and social dangers and inconveniences. However, it is not clear whether Somali refugees' housing provides adequate protection from the physical, environmental and social dangers or inconveniences. In fact, Somali refugees may not be enjoying adequate housing since they are being compared to the urban poor of Uganda. Dimanin (2012) argues that Kisenyi is the biggest slum in Kampala, and slum dwellers are among the urban poor in Uganda. Therefore, the low income status of most Ugandans in Kisenyi positively impacted on the perception of Somali refugees' housing situation in particular and wellbeing in general.

As with peace and security, education and employment, Somali refugees are able to access housing, partly due to the non-discriminatory behaviours of Ugandans, especially house owners. For example, as mentioned by participants from the two FGD Somali refugees, Ugandan house owners rent out their houses as shops to 
Somali refugees. Additionally, Ugandan house brokers and Ugandan friends of Somali refugees give advice concerning housing to Somali refugees. Therefore, it is not necessarily due to Somali refugees' financial resources that they have access to housing. An individual might be willing to pay high rent, but the house owner may refuse to rent out his or her house, basing on grounds of race or ethnicity. This may easily happen with Somali refugees since they are physically different from Ugandans.

However, Somali refugees' long duration of residence in Uganda plays a role, since they are able to form friendships with Ugandans, which are utilised during house searches. The Somali refugees' long period of residence in Uganda has also enabled them to adapt to life in Kampala, which is very important during house searches. They are able to access housing without the services of Ugandan house brokers.

Although most Somali refugees were able to adequately meet the above needs (peace and security, housing, education and employment), there were some Somali refugees who were experiencing inadequate satisfaction of these needs. Some of these refugees have experienced discrimination, physical attacks and verbal abuses from Ugandans. Indeed there were some Somali refugees who were unemployed. For instance, in relation to peace and security, Khamiat (Somali refugee), in an individual interview, explained the issue of insufficient peace and security Somali refugees in Kisenyi thus:

We are not satisfied because we have been discriminated against or abused. Can life be satisfying when the people you are living with are abusing you? Somali girls go to markets for shopping, and whatever they have bought is snatched away by Ugandan thieves. They sometimes fight us; they call us Misumari (nails) because it sounds like Somali. This is abuse to us. These are the kind of challenges we are facing, but we are patient because problems are everywhere whether it is here or in Somalia. For instance, in Somalia, Somali women face many problems. They are raped in our presence and you cannot do anything to save them.

On the other hand, Swaib (Ugandan participant), offered the following explanation with regard to the peace and security Somali refugees in Kisenyi:

I realise that these people don't have peace because one Somali refugee may tell you that Ugandans have mistreated them. You see Ugandans didn't like them from the start. I think that is the problem that they are experiencing. Let me give you an example, I saw this with my own eyes. One man riding a motor cycle intentionally tried to knock down a Somali girl saying: "you, why don't you go back to Mogadishu?" It really pained me. But the Somali girl was strong enough; she didn't fall down. However, it pained me very much. So, I think these people don't have peace.

\section{Conclusions and implications}

This paper has shown that Somali refugees' wellbeing is mainly about objective elements (peace and security, housing, employment and education). These elements are seen to be human needs when analysed in relation to Doyal and Gough's THN 
formulation. They are considered as basic necessities of life (Doyal and Gough, 1991; Reader, 2005; Scott, 2012) to Somali refugees' living well. Somali refugees should have adequate access to them if they are to live well in Kisenyi. Indeed, the 1951 UNHCR refugee Convention lists housing and education as components of refugee welfare. It also lists employment as a right to refugees (UNHCR, 2007).

Furthermore, the paper has shown that in terms of satisfaction of these needs, most Somali refugees are perceived to have adequate satisfaction. The satisfaction to these needs is influenced by Somali refugees' financial resources from small and medium scale business enterprises and financial remittances from relatives and friends overseas. For instance, the financial resources contributed to the satisfaction of Somali refugees' housing, educational and employment needs. In addition, Somali refugees' wellbeing was influenced by the non-discriminatory and accepting host environment. This environment resulted in Somali refugees having peace and security, housing, employment and education. In addition, some Somali refugees met their housing, educational and employment needs using financial support from fellow Somali refugees within Kisenyi and abroad. Therefore, a combination of a nondiscriminatory host environment, financial resources and a culture of social support create a conducive environment that promotes and guarantees refugees' wellbeing.

We have seen that a non-discriminatory and accepting host environment played a significant role in Somali refugees' wellbeing. This is mainly due to the laws and policies that promote freedoms and rights of refugees. These laws and policies enabled Somali refugees to engage in activities that contribute to the satisfaction of their needs, and thus their wellbeing. One way that other refugee hosting countries can contribute to the wellbeing of refugees is by designing and implementing laws and policies that promote freedoms and rights of refugees. For instance, as a result of a right to gainful employment and engagement in commerce (GOU, 2006), Somali refugees were able to start small and medium scale business enterprises. It is these enterprises that enabled them to have access to financial resources, and these resources were used to secure wellbeing elements such as housing and education. Furthermore, freedom of movement and residence in any part of the country enabled Somali refugees to move from a refugee settlement (Nakivale) to an area (Kisenyi) with opportunities that can lead to self reliance. Therefore, refugees' rights and freedoms need to be promoted by the host communities through policy formulation and implementation.

Furthermore, although the majority of Somali refugees were perceived as living well, there were some who did not. This calls for a change in the government policy on urban refugees. As earlier noted, refugees in urban centres are expected to be selfreliant, neither receiving material support from the UNHCR nor the government (GOU, 2014). This does not augur well with the 2006 Refugee Act which gives refugees an option of applying to the Commissioner of Refugees to reside in any other part of Uganda other than the refugee settlements or transit centres (GOU, 2006). Therefore, the government and UNHCR should make some policy provisions for providing material support to urban refugees who are unable to be self-reliant or those who were once self-reliant but slip back. The policy requiring urban refugees to 
be self-reliant in some ways forces some refugees to live in refugee settlements because of their inability to be self-reliant in urban centres. This negatively affects their choices and freedom on where to reside.

\section{References}

ActionAid International Uganda, 2012. Lost opportunity? Gaps in youth policy and programming in Uganda. Kampala, ActionAid International Uganda

Alkire, B., 2005. Needs and capabilities, in Reader, S. (ed), The philosophy of need. Cambridge, Cambridge university press, pp. 229-251.

Barash, P.D. \& Webel, P.C., 2002. Peace and conflict studies. London, Sage publications.

Boeije, H., 2010. Analysis in qualitative research. London, Sage publications.

Braybrooke, D., 1987. Meeting needs: Studies in moral, political, and legal philosophy. New Jersey, Princeton university press.

Brunk, G.C., 2012. Shaping a vision: The nature of peace studies, in Webel, PC and Johansen, J (eds), Peace and conflict studies: a reader. London, Routledge, pp. $10-24$.

Clark, A.D., \& Gough, I., 2005. Capabilities, needs and wellbeing: Relating the universal and the local, in Manderson, L (ed), Rethinking wellbeing. Perth, API Network, pp. 45-68.

Correa-Velez, I., Gifford, M.S. \& Barnett, G.A., 2010. Longing to belong: Social inclusion and wellbeing among youth with refugee backgrounds in the first three years in Melbourne, Australia. Social science and medicine, 71(8) 1399-1408

Cortright, D., 2008. Peace: A history of movements and ideas. Cambridge, Cambridge university press.

Dean, H., 2010. Understanding human need: Social issues, policy and practice. Bristol, the policy press.

Dimanin, P., 2012. Exploring livelihoods of the urban poor in Kampala, Uganda: An institutional, community, and household contextual analysis. [Online] Available From:

http://www.actionagainsthunger.org/sites/default/files/publications/ACF_Uganda_ Kampala_Urban_Study-2012.pdf [Accessed 10 July 2014]

Divakalala, C., 2008. Contested notions of wellbeing: Peoples' and donors' perceptions in Batticaloa, Sri Lanka. Master's thesis, the Netherlands, Institute of Social Studies.

Doyal, L. \& Gough, I., 1991. A theory of human need. London, Macmillan.

Galtung, J., 2012. Positive and negative peace', in Webel, PC \& Johansen, J (eds), Peace and conflict studies: a reader. London, Routledge, pp. 75-80.

Gasper, D., 2004. The ethics of development: From economism to human development. Edinburgh University press.

Gasper, D., 2007. Conceptualising human needs and wellbeing' in Gough, I \& McGregor, A (eds), Wellbeing in developing countries: From theory to research. Cambridge, Cambridge University Press, pp. 47-70. 
Glesne, C., 2011. Becoming qualitative researchers: An introduction. New York, Pearson.

Gough, I., 2000. Global capital, human needs and social policies. New York, Palgrave.

Gough, I., 2003. Lists and thresholds: Comparing the Doyal-Gough theory of human need with Nussbaum's capabilities approach', WeD working paper 01. University of Bath.

Government of Uganda, 2006. The refugee Act 2006. Government of Uganda, Kampala.

Government of Uganda, 2008. The education (pre-primary, primary and postprimary) Act 2008. Government of Uganda, Kampala.

Government of Uganda, 2014. Department of refugees. [Online] Available From:http://opm.go.ug/departments/department-of-disaster-preparedness-

management-refugees/department-of-refugees.html [Accessed on 21 June 2014]

Green, J., \& Hart, L., 1999. The impact of context on data', in Barbour, S.R \& Kitzinger, J (eds), Developing focus group research: Politics, theory and practice. London, Sage publications, pp. 21-35.

Hennink, M, Hutter, I, \& Bailey, A., 2011. Qualitative research methods. London, Sage publications.

Jasinskaja-Lahti, I, Liebkind, K, \& Perhoniemi, R., 2006. 'Perceived discrimination and wellbeing: A victim study of different immigrant groups. Journal of community and applied social psychology, 16(4) 267-284

Marshall, C., \& Rossman, B.G., 2006. Designing qualitative research. London, Sage publications.

Morgan, L.D., 1997. Focus groups as qualitative research. London, Sage publications.

Omata, N., 2012. Refugee livelihoods and the private sector: Ugandan case study. Refugee Studies Centre, University of Oxford, Working Paper series No. 86.

O'Neill, J., 2011. The overshadowing of needs, in Rauschmayer, F, Omann, I., \& Fruhmann, J (eds), Sustainable development: Capabilities, needs, and well-being. London, Routledge, pp.45-64.

Phillips, D., 2006. Quality of life: Concepts, policy and practice. London, Routledge.

Rauschmayer, F., Omann, I., \& Fruhmann, J., 2011. Needs, capabilities and quality of life: Refocusing sustainable development, in Rauschmayer, F, Omann, I \& Fruhmann, J (eds), Sustainable development: capabilities, needs, and well-being. London, Routledge, pp. 19-44.

Reader, S., 2005. Aristotle on necessities and needs, In Reader, S., (ed), The philosophy of need. Cambridge, Cambridge university press, pp. 113-135

Scott, K., 2012. Measuring wellbeing: Towards sustainability? London, Routledge.

Strauss, A. \& Corbin, J., 1998. Basics of qualitative research: Techniques and procedures for developing grounded theory. London, Sage publications.

Uganda Bureau of Statistics, 2013. The Uganda national household survey 2012/13 [Online] Available From: http://www.ubos.org/publications/household/ [Accessed on 23 January, 2014].

UNHCR., 2007. Convention and protocol relating to the status of refugees. UNHCR, Geneva. 
UNHCR., 2014a. 25 years of global forced displacement. UNHCR, Geneva.

UNHCR., 2014b. UNHCR global appeal 2014-2015: Uganda. [Online] Available From: http://www.unhcr.org/528a0a268.html [Accessed on 10 September 2014]

Wiggins, D., 1998. Needs, values, truth: Essays in the philosophy of value. Oxford, Clarendon Press.

\section{Author Biography}

Moses Senkosi (PhD) is a lecturer in the Department of Development Studies, School of Arts and Social Sciences at Uganda Christian University. He holds a PhD in Social Change, Migration and Development from the University of Melbourne; a Masters in Social Work, McGill University; and a Bachelor of Social Work and Social Administration, Makerere University. His research interests include human needs, human wellbeing, human migration and social protection. 